\title{
Effect of 24-hrs of sleep deprivation on Central Auditory Processing in young people - A Quasi-Experimental study
}

\author{
Naziruddin Husamuddin', Shivayogappa S Teli² \\ ${ }^{1}$ Assistant Professor, Department of Physiology, Government Vellore Medical College, Vellore, TN, India, ${ }^{2}$ Professor \\ and Head, Department of Physiology, Sri Manakula Vinayagar Medical College and Hospital, Puducherry, India
}

Background: Adequate amount of sleep is the basic need for survival. It is a well-known fact that disturbed sleep, acute or chronic, deteriorates the homeostasis. Sleep deprivation (SD) produces many adverse health consequences by affecting almost all the organ systems and their functions. However, sufficient literature was lacking on the effect of SD on central auditory processing (CAP), especially the temporal resolution component in young individuals. Aims and Objective: Therefore, this study aimed to investigate the impact of 24-hrs of sleep deprivation on the temporal resolution ability of young healthy night-shift employees. Materials and Methods: It was a Pretest-posttest study design (Quasi-Experimental study) comprising sixty $(\mathrm{N}=60)$ healthy security staff. After the initial survey, Tuning fork tests and Pure Tone Audiometry were performed to rule out hearing loss. Temporal resolution was assessed twice (before and after SD) by Random Gap Detection test (RGDT) where a pair of pure tone was presented at different frequencies with 'intervals of silence' between each pair of tones and average time interval (in milliseconds) was taken. Data analysis was done by SPSS 24 software. Results: There was an increase in RGDT values after sleep deprivation $10.70 \pm 0.46$ (Mean $\pm S D$ ), but the difference was not significant ( $p$-value $=0.5172$ ) when compared with baseline values $10.65 \pm 0.48$ (Mean \pm SD). Conclusion: Based on the research findings, we conclude that 24-hours of acute sleep deprivation didn't show any negative impact on the temporal resolution component of CAP mechanism in young, healthy individuals.

Key words: Central auditory processing; Homeostasis; Pure tone audiometry; Random gap detection test; Sleep deprivation

\section{INTRODUCTION}

Sleep is a vital biologic process necessary for the survival of all living creatures. In human beings, an adequate amount of sleep is a fundamental requirement in everyday life for maintaining optimal health state i.e. Homeostasis. Existing literature on sleep provides us variety of definitions. In simple terms, sleep is defined as the state of unconsciousness from which a person can be aroused by sensory or other stimuli. ${ }^{1}$ Being essential for life, sleep plays an important role in optimal functioning of various physiological processes of nervous, immune, hormonal, cardiovascular, and other systems.
Inadequate sleep or sleep deprivation (SD) is a common problem in modern society affecting almost all humans irrespective of their professions. Numerous factors affect sleep that range from lifestyle factors to various medical conditions. Condensed sleep-time has been associated with many adverse health consequences, which include reduced quality of life, emotional distress, autonomic nervous system imbalance, somatic problems, behavior problems, performance reductions in physical and mental tasks, obesity, hypertension, diabetes mellitus, etc. ${ }^{2}$ However, there is a paucity of information on the effect of SD on auditory processing of sound stimuli in young, sleep-deprived adults. Interestingly, by online and

\section{Address for Correspondence:}

Dr. Shivayogappa S Teli, Professor and Head, Department of Physiology, Sri ManakulaVinayagar Medical College and Hospital,

Puducherry. Mobile: +91-8122557996. E-mail: shivateli222@yahoo.com 
literature search, we noticed that very few studies have explored this field.,

The normal hearing process requires accurate functioning of all parts of the ear and their associated neural networks from the cochlea to cortex. Auditory processing or Central Auditory Processing (CAP) is a term used to describe those neurophysiological mechanisms that occur in the auditory system in response to sound stimuli. CAP includes all those mechanisms that underlie the auditory proficiencies like sound localization and lateralization; auditory discrimination; auditory pattern recognition; temporal integration, temporal discrimination (e.g., temporal gap detection), etc. ${ }^{5}$

Temporal resolution is the ability of the auditory system to detect rapid and sudden changes in the sound stimulus or the shortest time interval necessary to discriminate between two acoustic stimuli. ${ }^{5-7}$ Therefore, temporal resolution testing is very essential when assessing auditory processing mechanism. There are several tests available for assessing temporal resolution. ${ }^{5}$

Various factors influence one's ability to comprehend, localize, and discriminate auditory information. Age, ${ }^{8}$ gender, ${ }^{3}$ profession, and systemic diseases ${ }^{7}$ are few amongst them. Based on the available literature and our knowledge, we hypothesized that acute SD would negatively affect temporal resolution ability of CAP mechanism. Therefore, this study aimed to investigate the impact of 24-hrs of sleep deprivation on temporal resolution ability of young healthy night-shift employees.

\section{MATERIALS AND METHODS}

This study was conducted in Sri Manakula Vinayagar Medical College and Hospital, Pondicherry after taking Research and Ethics Committee approval. It was a Pretest-posttest study design (Quasi-Experimental study) involving sixty $(\mathrm{N}=60)$ apparently healthy security staff. The institute is having a 'special security department' with 110 staff members working for the safety of hospital, college, and the entire campus. The reason for selection of this population in the study was that their work timings is mainly 12 -hrs duty shift basis; an entire week day-time duty (from morning 8am to evening 8pm) and the following week night-time duty (evening $8 \mathrm{pm}$ to morning 8am). On the day of duty-shift, each staff works for 24 hours.

At the beginning, principal investigator interacted with the security staff $(\mathrm{N}=50)$ at a common place and their convenient time and explained the study procedure and purpose. Similarly, another interactive session was arranged with the remaining staff $(\mathrm{N}=52)$ after a week gap. Few didn't attend the sessions. Participation in the study was entirely voluntary and written consent was taken from all. Information regarding their age, gender, height, weight, years of service, duty timings, health status (presence of DM, Hypertension, psychiatric problems etc), sleep habits, medication history, and substance abuse were collected by using semi-structured questionnaire. Their contact numbers were also collected for communication. Individuals with the history of diabetes mellitus, hypertension, mental illness, sleep disorders, hearing loss, drug abuse, head injury, and ototoxic medications in the past 3 months (e.g., aminoglycosides) were excluded from the study.

Finally, sixty healthy security staff $(\mathrm{F}=9, \mathrm{M}=51)$ were included in the study who regularly worked on weekly dutyshift basis. We also prepared a list of all the participants and their duty-timings so that they can be invited easily for investigation. We chose duty-shift day for research purpose as study subjects were awake for $24 \mathrm{hrs}$ without sleep. There will be two 'patrolling security staff' in the hospital campus who make two rounds every night at 12 am and 4 am to ensure all the concerned security staff are alert during their night shift duty. All investigations were done in the Department of Otorhinolaryngology in the presence of principal investigator who clearly explained the procedures to all participants beforehand.

Tests for hearing, like Tuning fork tests (Rinne's and Weber's test) and Pure Tone Audiometry (PTA) were performed to rule out any hearing loss. Tuning fork tests were done as per standard guidelines. PTA was done using instrument - ALPS AD 2100 (advanced digital audiometer).

A pure tone was presented to each test-ear separately (non-test ear masked) through an earphone and the lowest intensity in decibels (dB) at which this tone was perceived $50 \%$ of the time was measured. The procedure was repeated at specific frequencies from 250 to 8000 hertz (Hz, or cycles per second) for each ear, and the thresholds were recorded on an audiogram. ${ }^{9,10}$

Central auditory processing, particularly temporal resolution, can be assessed by two methods; Random Gap Detection test (RGDT) and the Gaps-In-Noise (GIN), both are reliable in terms of sensitivity and specificity. ${ }^{5-7,11-13}$ We selected RGDT (MATLAB software) as it was available and feasible to our set-up. RGDT is the shortest time interval that an individual identifies when a pair of pure tone was presented at the frequencies 500, 1000, 2000 and $4000 \mathrm{~Hz}$ with intervals of silence between each pair of tones. The participants were instructed to respond with 
a hand movement if they heard one or two tones. The time interval included was $2,5,10,15,20,25,30$, and 40 milliseconds. ${ }^{5-7,11-13} \mathrm{All}$ participants were given a 'practice session' initially at different frequencies and the final 'test session' was recorded afterwards.

Both, PTA and RGDT were done twice with 24 hrs gap between two measurements; first recording was done at $8 \mathrm{am}$ in the morning on duty-shift day and the second recording was done next day morning at $8 \mathrm{am}$.

\section{Statistical analysis}

Data were analyzed using SPSS 24 software and two-tailed paired student " $t$ " test was applied for comparison before and after sleep deprivation. 'P' Value $<0.05$ was taken as significant.

\section{RESULTS}

Out of 110 staff, $102(92.72 \%)$ participated in the initial interactive session and survey. After considering inclusion and exclusion criteria and their willingness, 60 individuals voluntarily agreed to take part in the study (response rate $58.82 \%)$. The mean age of participants was $23.1 \pm 1.33$ (Mean \pm SD). M: F ratio was 85\% (N=51) and 15\% (N=09) respectively.

Results of Tuning fork tests were normal in all individuals without any hearing abnormalities. Participants' average hearing threshold levels in decibels (dB) before and after sleep deprivation are given in Table 1. There was no significant difference in the hearing threshold after $24 \mathrm{hrs}$ of sleep deprivation.

Results of auditory processing testing are given in Table 2 . Though, there was an increase in RGDT values (in

\begin{tabular}{|c|c|c|c|}
\hline Ear & $\begin{array}{c}\text { BSD }^{*} \\
(M e a n \pm S D)\end{array}$ & $\begin{array}{c}\text { ASD }^{* *} \\
(M e a n \pm S D)\end{array}$ & $\begin{array}{c}\mathbf{P} \\
\text { value }^{\star * * *}\end{array}$ \\
\hline Right ear & $15.56 \pm 2.39$ & $15.49 \pm 2.35$ & 0.2153 \\
\hline Left ear & $14.58 \pm 2.20$ & $14.72 \pm 2.23$ & 0.0532 \\
\hline
\end{tabular}

\begin{tabular}{lcc}
$\begin{array}{l}\text { Table 2: Random Gap Detection Test values of } \\
\text { study participants }(\mathbf{n}=60)\end{array}$ & $\begin{array}{c}\mathbf{P} \\
\text { ASD }\end{array}$ \\
\hline $\begin{array}{l}\text { BSD }^{* *} \\
\text { (Mean } \pm S D)\end{array}$ & $($ Mean $\pm S D)$ & value $^{* * *}$ \\
\hline $10.65 \pm 0.48$ & $10.70 \pm 0.46$ & 0.5172 \\
\hline
\end{tabular}

*BSD=before sleep deprivation, $* * A S D=$ after 24 hrs sleep deprivation, $* * * P<0.05$ significant milliseconds) after sleep deprivation (10.70 \pm 0.46$)$, but the difference was not significant when compared with baseline values $(10.65 \pm 0.48)$.

\section{DISCUSSION}

The purpose of this study was to investigate the impact of acute sleep deprivation on central auditory processing i.e. temporal resolution ability in young healthy sleep-deprived individuals. The findings of our study indicate that a short duration (24 hrs) of sleep disturbance will have a negative impact on an individual's ability to differentiate the auditory stimuli. More particularly, it affected the temporal resolution of CAP as evidenced by the differences in RGDT recordings before and after sleep disruption. The average time interval required to discriminate between two acoustic stimuli was increased after sleep deprivation. Our study findings are similar to other researchers who had also noticed significant changes in RGDT with sleep deprivation. ${ }^{3,4}$ However, the RGDT values in our study were not statistically significant.

It is a well-known fact that disturbed sleep, whether acute or chronic, deteriorates the homeostasis. Barely, there is any physiologic process or an organ system in the body which is left untouched by disturbed sleep. In the nervous system, SD affects various cortical and subcortical structures of the brain and alters the way they function under normal conditions. It particularly influences the functioning of frontal lobe (attention, concentration, language expression, and perception) and temporal lobe (memory, mood, behavior, sound perception and the processing of auditory information). ${ }^{3}$ Previous studies have also mentioned that SD affects temporal processing by principally disturbing the circuits involving prefrontal cortex (PFC), particularly left side ${ }^{14,15} \mathrm{Aforementioned} \mathrm{neurophysiological} \mathrm{alterations}$ in the brain might be the reasons for changes observed in auditory temporal resolution testing in our study and also by other researchers. ${ }^{3,4}$

It is also important to notice that, we could not observe any significant changes in temporal processing after SD. We consider it could be due to differences in the age of study participants and sample size. With increasing age, listening skills get affected due to changes in both peripheral and central auditory systems. It can be attributed to age-related changes in the organ of Corti (loss of hair cells and stria vascularis) and neural cells of the auditory pathway. As a result, older individuals experience listening difficulties because of slow neural processing and reduced coding of incoming temporal information. ${ }^{8,11}$ This might be one of the reasons, we believe, for not getting significant change in our study. Another reason is we had a comparatively 
bigger sample size. A higher sample size always increases the significance level of the results. Moreover, the discrepancies observed across different populations may be due to several endogenous and exogenous factors, such as the period without sleep, circadian rhythms, and personal motivation, as well as behavioral and personality characteristics. $^{3}$

\section{Limitations of the study}

Firstly, we could not check the participants' sleep habits during their duty hours. It was practically impossible for the investigators to supervise every single participant for 24-hrs. On the day of duty shift, each staff reported that they worked 24-hrs without sleep. We believe that what participants and Patrolling staff reported to us was true.

Secondly, we couldn't monitor participants' personal habits like drinking coffee during their duty hours. It is a common practice among the shift workers to sip coffee at regular intervals to keep them alert and energized, especially during nighttime. Coffee contains caffeine which is a known neuro-stimulant to enhance mood and performance.

Caffeine has been shown to improve neural transmission in both peripheral and central brain auditory pathways and produce a significant alerting and mood enhancing effects in sleep-deprived individuals. ${ }^{16-18}$ It seems that caffeine exerts its beneficial effect on wakefulness and task performance mainly by activating cholinergic neurons in the forebrain and inhibiting sleep-promoting neurons in the hypothalamus. ${ }^{19}$

Lastly, we did not conduct any cognitive or attention assessment in our study. It is also possible that the changes seen in RGDT in our study might have occurred due to cognitive and/or attention deficits in sleepdeprived individuals rather than impairement of CAP mechanism itself.

\section{Implications of the study}

The results of this study revealed that short period of sleep deprivation would negatively affect the temporal resolution and thereby, CAP mechanism of young people. Although, such changes were not statistically significant, it is hard to explain how young people's brain adapts to sleep deprivation. Nevertheless, this study paves the way for future investigations on central auditory processing in young population.

\section{CONCLUSION}

Based on the research findings, we conclude that 24 hours of sleep deprivation didn't produce any impact on the temporal resolution ability of CAP mechanism in young healthy individuals.

\section{ACKNOWLEDGEMENT}

We would like to express our gratitude to all the security staff of our institute for their cooperation and to the Department of Otorhinolaryngology for their technical assistance during the study.

\section{REFERENCES}

1. Vaz M, Kurpad A and Raj T. Guyton and Hall Text Book of Medial Physiology. $2^{\text {nd }}$ South Asia Edition. RELX India Private Limited; Elsevier Inc, 2016, P849.

2. Medic G, Wille M and Hemels ME. Short- and long-term health consequences of sleep disruption. Nat Sci Sleep. 2017; 9:151-161.

https://doi.org/10.2147/NSS.S134864

3. Liberalesso PBN, D'Andrea KFK, Cordeiro M, Zeigelboim BS, Marques JM and Jurkiewucz AL. Effects of sleep deprivation on central auditory processing. BMC Neurosci. 2012; 13- 83. https://doi.org/10.1186/1471-2202-13-83

4. Arora A, Bhat JS, Raj D, Kumar A and Kumar K. The Effect of Acute Sleep Deprivation on Temporal Processing and Frequency Resolution in Normal Healthy Adults. IntAdv Otol. 2014; 10(2): 134-137.

https://doi.org/10.5152/iao.2014.32

5. American Speech-Language-Hearing Association. (2005). (central) auditory processing disorders [Technical Report]. Available from: https://www.asha.org/content. aspx?id=10737450473

6. Elena Z, Pontin GA, Fraga TML and Jane AB. Performance of normal young adults in two temporal resolution tests. PróFono R. Atual. Scient. 2008; 20(1):19-24.

https://doi.org/10.1590/S0104-56872008000100004

7. Iliadou VV, Bamiou DE, Chermak GD and Nimatoudis I. Comparison of two tests of auditory temporal resolution in children with central auditory processing disorder, adults with psychosis, and adult professional musicians. International Journal of Audiology. 2014:53(8):507-513.

https://doi.org/10.3109/14992027.2014.900576

8. Gordon-Salant S, Fitzgibbons PJ and Yeni-Komshian GH. Auditory Temporal Processing and Aging: Implications for Speech Understanding of Older People. Audiol Res. 2011;1(1):e4.. https://doi.org/10.4081/audiores.2011.e4

9. Wikipedia contributors. Pure tone audiometry. Wikipedia, The Free Encyclopedia; 2019 Nov 27, 13:34 UTC.

https://en.wikipedia.org/w/index.php?title=Pure_tone_ audiometry\&oldid=928200989.

10. Saunders AZ, Stein AV, Shuster NL. Audiometry. In: Walker HK, Hall WD, Hurst JW, editors. Clinical Methods: The History, Physical, and Laboratory Examinations. 3rd edition. Boston: Butterworths; 1990. Chapter 133. https://www.ncbi.nlm.nih.gov/books/NBK239/

11. Braga BHC, Lillian DP and Karin DW. Normality criteria for temporal resolution tests: random gap detection test and gapsin-noise. Rev. CEFAC. 2015; 17 (3): 836-846. https://doi.org/10.1590/1982-021620158114. 
12. Robert Keith. Gap Detection. 2003 January.

https://www.audiologyonline.com/ask-the-experts/gapdetection-641

13. Musiek F. Introduction to Temporal Processing, Its Applications to CAPD, and other Aspects of Neuroaudiology. 2016, June https://www.audiologyonline.com/articles/introduction-totemporal-processing-its-20238

14. Patrick Y, Lee A, Raha O. Pillai K, Gupta S, Sethi S, et al. Effects of sleep deprivation on cognitive and physical performance in university students. Sleep and Biol Rhythms. 2017; 15: 217-225. https://doi.org/10.1007/s41105-017-0099-5

15. Babkoff $H$, Zukerman $G$, Fostick $L$ and Ben-Artzi E. Effect of the diurnal rhythm and $24 \mathrm{~h}$ of sleep deprivation on dichotic temporal order judgment. Journal of Sleep Research. 2005; 14: 7-15. https://doi.org/10.1111/j.1365-2869.2004.00423.x

16. Dixit A, Vaney $\mathrm{N}$ and Tandon OP. Effect of caffeine on central auditory pathways: An evoked potential study. Hearing Research. 2006; 220(1-2): 61-66.

https://doi.org/10.1016/j.heares.2006.06.017.

17. Tavanai E, Farahani S, Ghahraman MA, Soleimanian $S$ and Jalaie S. Effects of Caffeine on Auditory- and Vestibular-Evoked Potentials in Healthy Individuals: A Double-Blind PlaceboControlled Study. J Audiol Otol. 2020 ;24(1):10-16. https://doi.org/10.7874/jao.2019.00227

18. Barry RJ, Johnstone SJ, Clarke AR, Rushby JA, Brown CR and McKenzie DN. Caffeine effects on ERPs and performance in an auditory Go/NoGo task. Clin Neurophysiol. 2007; 118(12):2692-2699. https://doi.org/10.1016/j.clinph.2007.08.023

19. Boonstra TW, Stins JF, Daffertshofer A Beek PJ. Effects of sleep deprivation on neural functioning: an integrative review. Cell Mol Life Sci. 2007; 64: 934.

https://doi.org/10.1007/s00018-007-6457-8

\section{Authors' Contribution:}

NH-Developed the concept and design of the study, Review of literature and preparation of first draft of manuscript, collection of data and analysis; SST-Review

of literature and statistical analysis, critical revision of intellectual content and preparation of final version of manuscript for publication

Work Attributed to

Department of Physiology, Sri Manakula Vinayagar Medical College and Hospital, Puducherry-605107.

Orcid ID:

Dr. Naziruddin Husamuddin- (i) https://orcid.org/0000-0002-0637-1035

Dr. Shivayogappa S Teli- (i) https://orcid.org/0000-0002-0206-8303 